\title{
Perceived Health in Patients with Primary Immune Deficiency
}

\author{
Filiz Odabasi Seeborg ${ }^{1}$ (D) Roann Seay ${ }^{2} \cdot$ Marcia Boyle $^{3} \cdot$ John Boyle $^{3} \cdot$ \\ Christopher Scalchunes $^{3} \cdot$ Jordan Scott Orange $^{1}$
}

Received: 21 February 2015 / Accepted: 16 September 2015 / Published online: 9 October 2015

(C) The Author(s) 2015. This article is published with open access at Springerlink.com

\begin{abstract}
Purpose Perceived health $(\mathrm{PH})$ is a subjective measure of global health of individuals. While many studies have evaluated outcomes in patients with primary immune deficiency (PID), published literature evaluating $\mathrm{PH}$ among patients with PID is sparse. We evaluated the results of the largest selfreported survey of patients with PID to determine the factors that may contribute to differences in PH.

Methods Data from a National Survey of Patients with Primary Immune Deficiency Diseases conducted by the Immune Deficiency Foundation was studied. Multivariate logistic regression was employed for data analysis.

Results Thirty percent of the patients perceived their health status as excellent or very good (EVG), $31 \%$ as good $(\mathrm{G})$, and $39 \%$ as fair, poor or very poor (P). Older patients were less likely to have EVG-PH compared to G-PH. Ones with college degrees were more likely to have P-PH compared to G-PH, and less likely to have EVG-PH. Patients who were acutely ill and hospitalized in the past 12 months, ones with limited activity, and chronic diseases, were more likely to have PPH compared to G-PH. Patients with "on demand" access to specialty care and ones on regular IVIG had higher OR of having EVG-PH as opposed to G-PH. Patients cared for
\end{abstract}

Filiz Odabasi Seeborg

filizo@bcm.edu

1 Department of Pediatrics, Section of Immunology, Allergy and Rheumatology, Baylor College of Medicine and Texas Children's Hospital, 1102 Bates Ave. Suite 330, Houston, TX 77030, USA

2 The University of Texas Health Science Center, School of Public Health, Houston, TX, USA

3 Immune Deficiency Foundation, Towson, MD, USA mostly by an immunologist were less likely to have P-PH compared to G-PH.

Conclusions Our results emphasize the importance of $\mathrm{PH}$ in clinical practice. We suggest that recognizing the factors that drive PH in patients with PID is important for the development of disease prevention and health promotion programs, and delivery of appropriate health and social services to individuals with PID.

Keywords Perceived health $\cdot$ health status $\cdot$ primary immune deficiency $\cdot$ health survey $\cdot$ immunoglobulin

\section{Introduction}

Perceived health is a subjective measure of global health of individuals. There is a clear difference between the real $\mathrm{PH}$ assessments and questions regarding the prevalence of diseases. The $\mathrm{PH}$ assessment reflects individuals' integrated $\mathrm{PH}$, including the biological, psychological, cultural, and social dimensions, which is inaccessible to any external observer [1-3]. In other words, they cannot be easily detected by health care professionals. Perceived health status has been extensively used in epidemiologic studies as a broad indicator of health-related well-being [4-6]. It is an important predictor of a number of outcomes, such as new morbidity, functional ability, health care utilization $[7,8]$, recovery from illness [9], and physician ratings of health [10]. It may encompass aspects that are difficult to capture clinically, such as incipient disease, physiological and psychological reserves, and social function [11-13]. Moreover, it is an important and reliable indicator of quality of care as well as patient satisfaction, and quality improvement [14]. Existing evidence supports that patients in better health tend to report greater satisfaction with 
their health status and health care than patients in poor health [15]. Numerous epidemiological studies have reported an association between PH and mortality from all causes [3,16-19] while others have shown it to be associated with specific chronic diseases such as musculoskeletal, cardiovascular, and psychiatric disorders [20]. Perceived health may be influenced by age and gender differences as well as social, environmental and personal factors $[1,21]$. For example, individuals who consider themselves to be in poor health may be more likely depressed, may have disabilities, may be leading less productive and fulfilling lives, or may not be receiving the health care that they need.

Perceived health, also known as "self-assessed health", "self-rated health", "self-evaluated health", or "subjective health", has been evaluated and described in several patient populations with chronic conditions including systemic lupus erythematous [22], chronic obstructive pulmonary disease [23], inflammatory bowel disease [24], asthma [25], and cancer [14]. However, published literature evaluating patient-reported outcome measures related to patients with PID is sparse [26,27], and none have specifically analyzed $\mathrm{PH}$. As a chronic disease, complications of PID bring about major challenges to health and social life of individuals affected by it. Understanding the health status of this population and the factors driving it is important for the development of disease prevention and health promotion programs, as well as the delivery of appropriate health and social services to individuals with PID. Therefore, we aimed to describe general characteristics and health of a national U.S. sample of patients with a variety of PID diagnoses, and define the variables that influenced $\mathrm{PH}$ among patients with PID.

\section{Methods}

\section{Data Source}

Investigations were based on data obtained from the Second National Survey of Patients with Primary Immune Deficiency Diseases in America, which was conducted by the Immune Deficiency Foundation (IDF) in 2002. The IDF contact database provided the first stage in the construction of the sampling frame. This large national sample consisted of 5922 adults and children with PID across U.S. Patients were mailed a two-page self-administered questionnaire, along with a cover letter explaining the purposes of the survey. A total of 1587 individuals completed and returned the questionnaire $(26.8 \%) .49$ cases were identified as deceased patients with PID, and the remainder was patients without PID but with other diagnoses such as autoimmune disease. Therefore data were collected from only 1526 patients with PID.

\section{Variables of Interest}

The outcome measure, perceived health status, was assessed on a 6 -point Likert scale $(1=$ excellent, $2=$ very good, $3=$ good, $4=$ fair, $5=$ poor, $6=$ very poor) based on the question "Would you describe his/her current health status as excellent, very good, good, fair, poor, or very poor?". The excellent and very good response categories, as well as the fair to very poor categories were combined, creating three comparison groups: excellent to very good (EVG), good $(\mathrm{G})$, and fair to very poor which is referred to hereafter as poor-rated $(\mathrm{P})$ health. Each indicator of $\mathrm{PH}$ status was coded according to a trinomial outcome variable $(0=$ good, $1=$ excellent /very good, $2=$ fair/ poor/very poor). Independent variables were grouped into the following: Sociodemographic, PID diagnosis (type), current health status, comorbidities, health care access, and IVIG treatment. The sociodemographic variables included: age, gender, education status (less than college, college and higher), questionnaire respondent (adult patient, parent/caregiver, both), employment status (unemployed, employed, other), and number of children with PID in the household (none vs. at least one). The very first question asked who the respondent was in relation to a patient with a PID. If there were no children in the household with PID, it was instructed that patients with PID should answer about themselves. If they were not patients with PID then it was instructed that they should answer questions about the oldest child in the household with PID.

Patient sample had a number of PID diagnoses, and included common variable immunodeficiency (CVID), IgA deficiency, IgG subclass deficiency, $\mathrm{X}$-linked agammaglobulinemia (XLA), severe combined immunodeficiency (SCID), chronic granulomatous disease (CGD), Hyper IgM Syndrome (HIM), Wiskott Aldrich Syndrome (WAS), and DiGeorge Syndrome (DGS) (Fig. 1). Common variable immunodeficiency accounted for the majority of the patient sample (about $54 \%$ ), followed by $\operatorname{IgG}$ subclass and $\operatorname{IgA}$ deficiencies, and all other diagnoses were smaller proportions. Because of the large distribution differences within PID diagnoses, and CVID comprising the majority of the diagnoses we observed a better fit in logistic regression modeling when diagnoses were reclassified in two groups (CVID vs. non-CVID). Therefore items related to PID diagnosis were assessed as follows: having CVID (yes/ no), having a family member with PID (yes/ no), having infections prior to diagnosis with PID (yes/ no), reason for initial testing for PID (family history, routine checkup, recurrent infections, unusual infections, serious infections), and number of hospitalizations prior to diagnosis with PID (none vs. at least one). Current health was elucidated through three questions and included: having acute illness in the past 12 months (yes/ no), hospitalization in the past 12 months (yes/ no), and limitation of physical activity (none, slight, moderate, severe). Comorbidities included: having permanent functional impairment (yes/ no), other chronic disease 
Specific PID Diagnoses

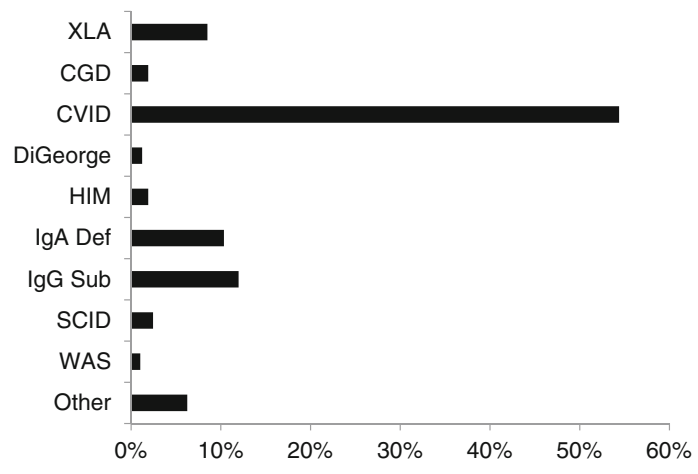

XLA: X-linked agammaglobulinemia; CGD: Chronic granulomatous disease; CVID: Common variable immunodeficiency; HIM: Hyper IgM Syndrome; IgG Sub: IgG subclass deficiency; SCID: Severe combined immunodeficiency; WAS: Wiscott Aldrich Syndrome

Fig. 1 National Survey of Patients with Primary Immune Deficiency, 2002: Primary Immune Deficiency Diagnoses

(yes/ no), cancer/leukemia (yes/ no), hepatitis (yes/ no), or neurological disease (yes/ no). Health care access was assessed by five questions and included: physician visited most often for health care (specialist in immunology vs. other specialist), setting of primary care visit (private office vs. others), having "on demand" access to specialist care as needed (yes/ no), having visited immunologist in the past 12 months (yes/ no), insurance status (private vs non-private). Treatment status with IVIG was assessed by the following questions: ever receiving IVIG on a regular basis (yes/no), length of regular IVIG treatment, current treatment status with IVIG (yes/no), frequency of IVIG treatment (every 2 weeks or more often, every 3 weeks, every 4 weeks, every 5 weeks, every 6 weeks or more), side effects of IVIG treatment (yes/ no). Because the data related to IVIG treatment was sparse $(<15 \%)$ (except for the question that addressed whether the patient has ever received regular treatment with IVIG), other variables of IVIG treatment were excluded from the analysis.

\section{Statistical Analysis}

To model our multinomial scaled outcome, we employed the backwards elimination method to build our multinomial logistic regression model using Stata 12 (StataCorp, Inc., College Station, TX). We first conducted a univariable analysis of all the non-sparse variables, defined as variables with less than an $85 \%$ response rate, and retained the covariates with a $p$-value less than 0.25 . After determining the variables that belonged in our preliminary main effects model, we assessed whether age could be kept in the model as a continuous variable. We found that age in years was not linear and, thus, could not remain as a continuous variable in the model. Using the average age of our sample population as the cut-off point, we dichotomized age into less than 33 years old and greater than 33 years old.

Our final multinomial logistic regression model included covariates for age, gender, education, CVID diagnosis, infection prior to diagnosis, acute illness in the past 12 months, limitation, hospital stay in the past 12 months, hepatitis, other chronic diseases (not counting primary immune deficiency), access to care as needed, primary health care provider specialty, and ever having received regular IVIG treatments. To test how well our model fits the observed values in the IDF questionnaire, we ran the Hosmer-Lemeshow goodness of fit test. The Hosmer-Lemeshow goodness of fit test is a measure of lack of fit of our logistic regression model. Thus, rejection of the null hypothesis for the Hosmer-Lemeshow goodness of fit test indicates that the model we have built adequately fits our data.

When comparing patients who had EVG-PH versus patients who had G-PH, the summary goodness-of-fit statistic was 8.89 (degrees of freedom $[d f]=8, p$-value $=0.3519$ ). For patients who had P-PH versus patients who had G-PH, the summary goodness-of-fit statistic was $11.70(d f=8, p$-val$\mathrm{ue}=0.1653$ ). For both of these strata, the $p$-values indicate that we must reject the null hypothesis that the model is not a good fit to our data. Thus, we can conclude that our model is a good overall fit to the data.

\section{Results}

Of the 1526 PID survey respondents, $61.2 \%$ were adult PID patients, $36.7 \%$ were parents of a PID patient, and $2.1 \%$ were both adult PID patients and parents of a PID patient (Table 1). In cases where there was more than one person with PID in a household, it was necessary to direct the survey recipient on how to select a designated respondent for the survey. Thus, the questionnaire specified that if an adult patient had children with PID, the adult patient should answer the survey questions, rather than their affected children. If there were multiple children with PID in the household, and no adult patients with PID, the parent/caregiver was directed to answer the survey questions about the oldest child with PID. The reason for this selection procedure was to provide a sample with the longest diagnosis and treatment experience.

The vast majority of PID patients were White, nonHispanic (93.7\%). Approximately one-third of the patients were younger than 18 years old and another third were young adults between 18 and 44 years old with mean age of 33 years ( $\mathrm{SD} \pm 20.2$ ). The geographic distribution of the patient sample closely mirrored the total population of U.S. In comparing the proportion of the U.S. born patients who were born in a particular Census division to the percent of the U.S. population living in that division, the rates were almost identical for New England, Mid-Atlantic, South Atlantic, East and West South Central, and Mountain (Fig. 2).

More than half of the patients were females, which was similar to the general population. The majority of respondents (73\%) had completed college. Fifty four percent of the 
Table 1 Sociodemographic characteristics of respondents $(N=1526)$

\begin{tabular}{|c|c|}
\hline Characteristic & $\begin{array}{l}\text { Responden } \\
\mathrm{N}(\%)\end{array}$ \\
\hline \multicolumn{2}{|l|}{ Age (years) } \\
\hline \multicolumn{2}{|l|}{ Mean $33.2( \pm 20.2)$} \\
\hline $0-6$ & $150(10)$ \\
\hline $7-12$ & $195(13)$ \\
\hline $13-17$ & $135(9)$ \\
\hline $18-29$ & $210(14)$ \\
\hline $30-44$ & $315(21)$ \\
\hline $45-64$ & $435(29)$ \\
\hline$\geq 65$ & $60(4)$ \\
\hline \multicolumn{2}{|l|}{ Gender } \\
\hline Male & $638(42)$ \\
\hline Female & $880(57.9)$ \\
\hline \multicolumn{2}{|l|}{ Education } \\
\hline 8th grade or less & $90(6)$ \\
\hline Some high school & $45(3)$ \\
\hline Completed high school & $270(18)$ \\
\hline Some college & $464(31)$ \\
\hline Completed college & $345(23)$ \\
\hline Graduate degree & $285(19)$ \\
\hline \multicolumn{2}{|l|}{ Employment } \\
\hline Employed & $806(54.3)$ \\
\hline Unemployed & 325 (21.9) \\
\hline Other & $353(23.8)$ \\
\hline \multicolumn{2}{|l|}{ Race } \\
\hline White, Non Hispanic & $1408(93.7)$ \\
\hline Others & $95(6.3)$ \\
\hline \multicolumn{2}{|l|}{ Respondent } \\
\hline Adult & $931(61.2)$ \\
\hline Parent of a child with PID & $558(36.7)$ \\
\hline Both & $32(2.1)$ \\
\hline \multicolumn{2}{|l|}{ Perceived health } \\
\hline Excellent/very good & $444(30)$ \\
\hline Good & $459(31)$ \\
\hline Fair/poor/very poor & $601(39)$ \\
\hline
\end{tabular}

patients were employed, $21.9 \%$ were unemployed, and the others were homemakers, students, or did not respond with an employment status. Thirty percent of the patients perceived their health status as excellent or very good, $31 \%$ as good, and $39 \%$ as fair, poor or very poor.

A patient's PH status, which divided the respondents into approximate thirds (excellent/very good, good, and fair/poor), was used to characterize univariate associations between the characteristics of patients with PID. Perceived health was significantly linked to sociodemographic characteristics including age, gender, education level, type of respondent, and employment status (Table 2). When evaluating the sociodemographic characteristics of PID patients with regards to PH $47.5 \%$ of women, but only $29.6 \%$ of men, reported P- PH $(p<0.0001)$. Conversely, a higher percentage of men than women described their health as excellent or very good (39.4 \% and $22.4 \%$, respectively). Older patients were more likely to report $\mathrm{P}-\mathrm{PH}$, although this was difficult to separate from reporting by a caretaker as opposed to the patients themselves $(p<0.0001)$. More patients with a college degree had poorer $\mathrm{PH}$ when compared to those with less education. Homemakers and students had poorer PH than employed patients and non-homemaker unemployed patients $(p<0.0001)$. Households with a child having PID had better PH when compared to those without any child with PID (39.3 and $22.8 \%$, respectively, $p<0.001)$. Conversely, households without a child having PID reported poorer PH when compared to those with a child having PID (47.8 and $28.7 \%$, respectively, $p<0.0001$ ).

In addition, $\mathrm{PH}$ (in either direction) was significantly associated with a number of other patient characteristics including the number of children with PID in the household, CVID diagnosis, infections prior to diagnosis, reason for initial testing for PID, number of hospitalizations prior to diagnosis with PID, presence of acute illnesses and hospitalization in the past 12 months, limitation of daily physical activity, comorbid conditions, "on demand" access to specialist care, the specialty of the physician caring for the patient (immunologist versus other specialty), and possession of health insurance (Table 3). Having had a visit with immunologist in the past 12 months, the particular setting of physician visits (i.e., doctor's office, clinic, or hospital), and whether or not the patient has ever received regular IVIG replacement therapy were not significantly associated with $\mathrm{PH}$ when considered as individual variables (Table 3).

Since our outcome variable is trinomial (i.e., three levels of $\mathrm{PH})$, we used a multivariate logistic regression analysis approach to determine if there were significant drivers of $\mathrm{PH}$ in light of all of the potentially mitigating and confounding variables. These were calculated as odds ratios (OR) together with their $95 \%$ confidence intervals (CI). Using backwards elimination, all covariates with a $p$ value of less than 0.25 in the univariate analysis were included in the preliminary multivariate model, and the model was constructed by eliminating the variables, one at a time, based on lack of significance in the presence of other covariates. This method of elimination continued until all variables in the remaining model with either significant or deemed clinically significant. Thus, the final multivariate model included age, gender, education status, having a diagnosis of CVID, infections prior to diagnosis with PID, acute illness and hospitalization in the past 12 months, limitation of physical activity, hepatitis, chronic diseases, "on demand" access to specialist care, the specialty of the physician caring for the patient and having ever received regular IVIG treatment (Table 4). When all of these factors that might impact $\mathrm{PH}$ were taken into consideration and adjusted ORs are 


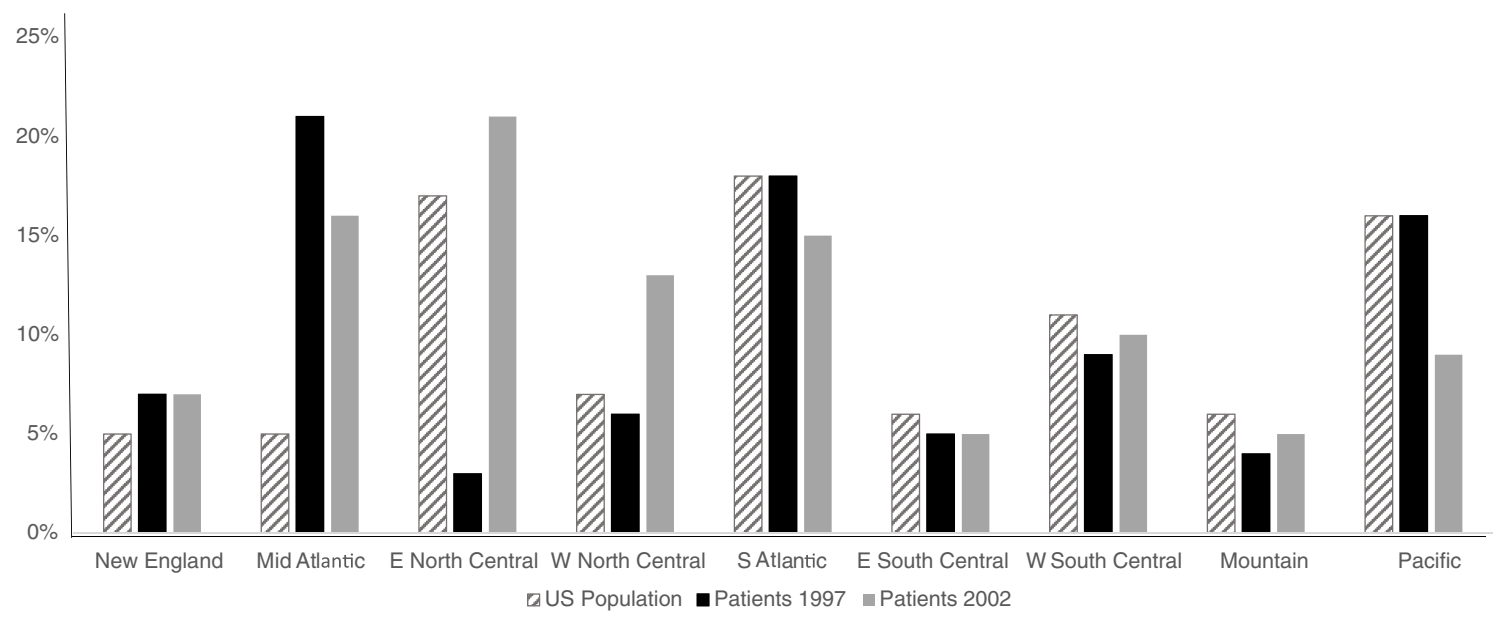

Fig. 2 Distribution of 1997 and 2002 National Survey of Patients with PID and overall US population by region

calculated, significant associations between $\mathrm{PH}$ and gender, respondent type, employment status, CVID diagnosis, infections and number of hospitalizations prior to PID diagnosis, reason for initial testing for PID, all comorbidities except chronic diseases, and insurance status were no longer observed.

Some covariates, however, did survive multivariate analyses and thus remain as potentially independent drivers of $\mathrm{PH}$. Age was associated with PH, but only when comparing EVG-
PH to G-PH. Respondents 33 years of age and older had lower odds of having EVG- PH (OR 0.68, $95 \%$ CI 0.48-0.98; $p=0.037$ as opposed to G-PH. Of note, $95.8 \%$ of patients 33 years of age and older were adult patients (data not shown).

Perceived health and education level were significantly associated. PID patients with a college degree were more likely to have P-PH as opposed to G-PH (OR 1.54, $95 \% \mathrm{CI} 1.12$ 2.13; $p=0.008$ ) and less likely to report EVG-PH (OR 0.65, $95 \%$ CI $0.46-0.90 ; p=0.009$ ).
Table 2 Comparison of sociodemographic characteristics of patients with PID by perceived health

\begin{tabular}{|c|c|c|c|c|c|c|}
\hline \multirow[b]{2}{*}{ Demographics } & \multicolumn{6}{|c|}{ Perceived health } \\
\hline & $\mathrm{N}$ & $\begin{array}{l}\text { Excellent/ } \\
\text { Very Good }\end{array}$ & $\mathrm{p}$ & $\begin{array}{l}\text { Good } * \\
\%\end{array}$ & $\begin{array}{l}\text { Fair/Poor/ } \\
\text { Very Poor }\end{array}$ & $\mathrm{p}$ \\
\hline & & $\%$ & & & $\%$ & \\
\hline Age (mean year \pm SD) & 1479 & $25.4( \pm 18.3)$ & 0.0001 & $31.8( \pm 20)$ & $39.5( \pm 19.4)$ & 0.0001 \\
\hline Gender & 1497 & & & & & \\
\hline Male $(\%)^{*}$ & & 39.4 & & 31.0 & 29.6 & \\
\hline Female (\%) & & 22.4 & 0.0001 & 30.2 & 47.5 & 0.0001 \\
\hline Education & 1476 & & & & & \\
\hline Less than college $(\%)^{*}$ & & 25.5 & & 29.9 & 44.6 & \\
\hline College \& higher (\%) & & 34.8 & 0.047 & 31.3 & 33.9 & 0.012 \\
\hline Questionnaire respondent & 1499 & & & & & \\
\hline Adult $(\%)^{*}$ & & 22.9 & & 29.5 & 47.6 & \\
\hline Parent (\%) & & 44.4 & 0.0001 & 31.7 & 26.9 & 0.0001 \\
\hline Both (\%) & & 13.3 & 0.109 & 43.3 & 43.3 & 0.231 \\
\hline Employment & 1464 & & & & & 0.0001 \\
\hline Unemployed $(\%)^{*}$ & & 36.5 & & 34.3 & 29.3 & \\
\hline Employed (\%) & & 36.7 & 0.99 & 34.5 & 28.9 & 0.900 \\
\hline Other $(\%)$ & & 6.4 & 0.0001 & 18.9 & 74.8 & 0.0001 \\
\hline $\begin{array}{l}\text { No of children with } \\
\text { PID in household }\end{array}$ & 1504 & & & & & \\
\hline None $(\%)^{*}$ & & 22.8 & & 29.4 & 47.8 & 0.0001 \\
\hline At least one $(\%)$ & & 39.3 & 0.001 & 32 & 28.7 & 0.0001 \\
\hline
\end{tabular}

*Reference

Significance level $p<0.05$ 
Table 3 Respondent characteristics by perceived health: Represented by distribution of characteristics and statistical significance level

\begin{tabular}{|c|c|c|c|c|c|c|}
\hline \multicolumn{7}{|l|}{ Perceived Health } \\
\hline & & $\begin{array}{l}\text { Excellent/ } \\
\text { very good }\end{array}$ & $\mathrm{p}$ & Good* & $\begin{array}{l}\text { Fair/poor/ } \\
\text { very poor }\end{array}$ & $\mathrm{p}$ \\
\hline Characteristics & $\mathrm{N}$ & $\%$ & & $\%$ & $\%$ & \\
\hline \multicolumn{7}{|l|}{ Diagnosis } \\
\hline \multirow[t]{3}{*}{ CVID } & 1504 & & 0.003 & & & 0.006 \\
\hline & No* & 17.1 & & 14.6 & 15.8 & \\
\hline & Yes & 12.4 & & 15.9 & 24.2 & \\
\hline \multirow{3}{*}{$\begin{array}{l}\text { Family member } \\
\text { with PID }\end{array}$} & 1476 & & 0.27 & & & 0.91 \\
\hline & No * & 22.7 & & 24 & 31.1 & \\
\hline & Yes & 7.3 & & 6.4 & 8.5 & \\
\hline \multirow{3}{*}{$\begin{array}{l}\text { Infection prior } \\
\text { to PID diagnosis }\end{array}$} & 1479 & & 0.002 & & & 0.06 \\
\hline & No* & 4.3 & & 2.4 & 2 & \\
\hline & Yes & 25.3 & & 28.2 & 37.8 & \\
\hline \multirow{7}{*}{$\begin{array}{l}\text { Reason for initial } \\
\text { testing for PID }\end{array}$} & 1501 & & & & & \\
\hline & Family history* & 2.8 & & 1.3 & 1.8 & \\
\hline & Check-up & 3.7 & 0.002 & 4.9 & 5.4 & 0.56 \\
\hline & Recurrent infection & 13.5 & 0.006 & 14.1 & 18.1 & 0.87 \\
\hline & Unusual infections & 2 & 0.48 & 1.3 & 2.2 & 0.54 \\
\hline & Serious infections & 3.7 & 0.001 & 5.3 & 6.5 & 0.75 \\
\hline & Other & 3.7 & 0.025 & 3.7 & 6.1 & 0.55 \\
\hline \multirow{5}{*}{$\begin{array}{l}\text { No of hospitalizations } \\
\text { prior to PID diagnosis }\end{array}$} & 1402 & & & & & \\
\hline & None* & 14.8 & & 13.7 & 12.6 & \\
\hline & $1-3$ & 11 & 0.81 & 10.6 & 9.8 & 0.97 \\
\hline & $4-6$ & 2.4 & 0.07 & 3.5 & 7.3 & 0.0001 \\
\hline & $>6$ & 3.4 & 0.04 & 4.9 & 13 & 0.0001 \\
\hline \multicolumn{7}{|l|}{ Current Health } \\
\hline \multirow{3}{*}{$\begin{array}{l}\text { Acute illness in past } \\
12 \text { months }\end{array}$} & 1504 & & 0.0001 & & & 0.0001 \\
\hline & $\mathrm{No}^{*}$ & 14 & & 6.2 & 3.6 & \\
\hline & Yes & 15.6 & & 24.3 & 36.3 & \\
\hline \multirow{3}{*}{$\begin{array}{l}\text { Hospitalization in } \\
\text { past } 12 \text { months }\end{array}$} & 1500 & & 0.0001 & & & 0.001 \\
\hline & $\mathrm{No}^{*}$ & 24.5 & & 21.2 & 23.9 & \\
\hline & Yes & 5 & & 9.3 & 16.1 & \\
\hline \multirow{5}{*}{$\begin{array}{l}\text { Limitation of } \\
\text { physical activity }\end{array}$} & 1488 & & & & & \\
\hline & None* & 21 & & 8.3 & 1.5 & \\
\hline & Slight & 7.3 & 0.0001 & 14.3 & 8.4 & 0.0001 \\
\hline & Moderate & 1.1 & 0.0001 & 6.5 & 17.3 & 0.0001 \\
\hline & Severe & 0.3 & 0.0001 & 1.2 & 12.8 & 0.0001 \\
\hline \multicolumn{7}{|l|}{ Comorbidities } \\
\hline \multirow{3}{*}{$\begin{array}{l}\text { Permanent organ } \\
\text { impairment }\end{array}$} & 1504 & & 0.0001 & & & 0.0001 \\
\hline & No* & 23 & & 2.1 & 18.9 & \\
\hline & Yes & 6.5 & & 9.9 & 21.1 & \\
\hline \multirow[t]{3}{*}{ Other chronic disease } & 1467 & & 0.0001 & & & 0.0001 \\
\hline & No* & 21.1 & & 14.2 & 9.7 & \\
\hline & Yes & 8.9 & & 16.3 & 29.9 & \\
\hline \multirow[t]{3}{*}{ Cancer/leukemia } & 1495 & & 0.12 & & & 0.004 \\
\hline & No* & 28.4 & & 28.8 & 35.3 & \\
\hline & Yes & 1.1 & & 1.9 & 4.5 & \\
\hline
\end{tabular}


Table 3 (continued)

\begin{tabular}{|c|c|c|c|c|c|c|}
\hline \multicolumn{7}{|l|}{ Perceived Health } \\
\hline & & $\begin{array}{l}\text { Excellent/ } \\
\text { very good }\end{array}$ & $\mathrm{p}$ & Good* & $\begin{array}{l}\text { Fair/poor/ } \\
\text { very poor }\end{array}$ & $\mathrm{p}$ \\
\hline \multirow[t]{3}{*}{ Hepatitis } & 1483 & & 0.05 & & & 0.006 \\
\hline & No & 28.7 & & 28.9 & 35.3 & \\
\hline & Yes & 0.9 & & 1.8 & 4.3 & \\
\hline \multirow[t]{3}{*}{ Neurological disease } & 1469 & & 0.0001 & & & 0.0001 \\
\hline & No & 27 & & 25.1 & 25.9 & \\
\hline & Yes & 2.9 & & 5.7 & 13.5 & \\
\hline \multicolumn{7}{|l|}{ Health care access } \\
\hline \multirow[t]{3}{*}{ Physician specialty } & 1504 & & 0.24 & & & 0.06 \\
\hline & Other & 18.5 & & 18 & 25.8 & \\
\hline & Immunology & 11 & & 12.6 & 14.2 & \\
\hline \multirow{3}{*}{$\begin{array}{l}\text { Setting of primary } \\
\text { care visit }\end{array}$} & 1504 & & 0.77 & & & 0.52 \\
\hline & Private office* & 19.2 & & 20.1 & 27.1 & \\
\hline & Others & 10.3 & & 10.4 & 12.8 & \\
\hline \multirow{3}{*}{$\begin{array}{l}\text { Access to specialist } \\
\text { care as needed }\end{array}$} & 1490 & & 0.0001 & & & 0.002 \\
\hline & No* & 1.1 & & 3.1 & 6.8 & \\
\hline & Yes & 28.5 & & 27.2 & 33.3 & \\
\hline \multirow{3}{*}{$\begin{array}{l}\text { Visit with immunologist } \\
\text { in past } 12 \text { months }\end{array}$} & 1495 & & 0.45 & & & 0.80 \\
\hline & No* & 9 & & 8.6 & 11.6 & \\
\hline & Yes & 20.6 & & 21.8 & 28.4 & \\
\hline \multirow[t]{4}{*}{ Insurance status } & 1487 & & 0.0001 & & & 0.002 \\
\hline & Private* & 26.2 & & 23.5 & 21.9 & \\
\hline & Non-private & 3.5 & & 6.8 & 17.1 & \\
\hline & None & 0.07 & & 0.3 & 0.7 & \\
\hline \multicolumn{7}{|l|}{ Treatment } \\
\hline \multirow[t]{3}{*}{ Regular IVIG treatment } & 1500 & & 0.97 & & & 0.11 \\
\hline & No* & 6.5 & & 6.8 & 7.3 & \\
\hline & Yes & 23 & & 23.8 & 32.6 & \\
\hline
\end{tabular}

*Reference

Significance level $p<0.05$

The occurrence of acute illness and hospitalization within the last 1 year were significantly associated with P-PH. Patients who were acutely ill and hospitalized in the past 12 months were more likely to have poor as opposed to G-PH (OR 1.20, $95 \%$ CI 1.24-3.21; $p=0.005$ and OR 1.48, $95 \%$ CI 1.05-2.07; $p=0.025$, respectively), and less likely to have EVG-PH (OR $0.45,95 \%$ CI $0.32-0.64 ; p<0.0001$, and OR $0.53,95 \% \mathrm{CI}$ $0.36-0.77 ; p<0.001$, respectively). A strong association was observed between $\mathrm{PH}$ and the limitation of physical activity as patients with restrictions had higher odds of reporting $\mathrm{P}-\mathrm{PH}$, and lower odds of describing EVG-PH. More strikingly, patients had worse $\mathrm{PH}$ if they had more limitation of physical activity. Patients with severe limitation had 51.37 times higher odds of having P-PH (OR 51.37, 95 \%CI 24.11-109.41; $p<0.001$ ) as opposed to moderate limitation (OR 14.16, $95 \%$ CI $7.92-25.31 ; p<0.001)$. The degree of limitation was also relevant as those with slight limitation as opposed to ones without limitation had worse PH (OR 2.92, 95 \%CI 1.66-5.14; $p<0.0001$ ).

Chronic disease also influenced health perception as patients with chronic disease such as bronchitis, malabsorption, and recurrent infections were more likely to have P-PH (OR 1.70, $95 \%$ CI 1.21-2.36; $p=0.002$ ) as opposed to EVG-PH (OR 0.56, $95 \%$ CI $0.40-0.78 ; p=0.001)$. Patients with "on demand" access to specialist care had 2.54 higher odds of reporting EVG-PH as opposed to G-PH (OR 2.54, $95 \%$ CI 1.27-5.06; $p=0.008$ ). An association between $\mathrm{PH}$ and "on demand "access to specialty care, however, was not observed when comparing P-PH to G$\mathrm{PH}$. Patients who were most often seen by an immunologist for care, however, (when compared to other specialties) were significantly less likely to have P-PH (OR 0.68, 95 \%CI 0.49 $0.94 ; p=0.020)$. Finally, patients who were receiving regular IVIG replacement therapy were more likely to have EVG-PH as opposed to G-PH (OR 1.61, 95 \%CI 1.07-2.42; $p=0.023$ ). 

logistic regression: Adjusted ORs relating variables to excellent/ very good $\mathrm{PH}$ and fair/poor/very poor versus good $\mathrm{PH}$ in patients with PID
Table 4 Results of multivariate

\begin{tabular}{|c|c|c|c|c|c|}
\hline & $N=1353$ & $\begin{array}{l}\text { Excellent/Very Good PH } \\
\text { Ref: Good PH } \\
\text { OR }(95 \% \text { CI })\end{array}$ & $\mathrm{p}$ & $\begin{array}{l}\text { Fair/Poor/Very Poor PH } \\
\text { Ref: Good PH } \\
\text { OR 95\%CI }\end{array}$ & $\mathrm{p}$ \\
\hline \multirow[t]{2}{*}{ Age (year) } & $<33^{*}$ & 1.0 & & 1.0 & \\
\hline & $\geq 33$ & $0.68(0.48-0.98)$ & 0.037 & $1.11(0.78-1.57)$ & 0.562 \\
\hline \multicolumn{6}{|l|}{ Gender } \\
\hline & Male* & 1.0 & & 1.0 & \\
\hline & Female & $1.02(0.73-1.43)$ & 0.896 & $0.87(0.62-1.24)$ & 0.447 \\
\hline \multicolumn{6}{|l|}{ Education } \\
\hline & Less than college* & 1.0 & & 1.0 & \\
\hline & College \& higher & $0.65(0.46-0.90)$ & 0.009 & $1.54(1.12-2.13)$ & 0.008 \\
\hline \multicolumn{6}{|l|}{ CVID } \\
\hline & No * & 1.0 & & 1.0 & \\
\hline & Yes & $0.72(0.51-1.02)$ & 0.066 & $1.35(0.96-1.90)$ & 0.086 \\
\hline \multicolumn{6}{|c|}{ Infections prior to PID diagnosis } \\
\hline & $\mathrm{No}^{*}$ & 1.0 & & 1.0 & \\
\hline & Yes & $0.62(0.36-1.07)$ & 0.086 & $1.66(0.87-3.17)$ & 0.125 \\
\hline \multicolumn{6}{|c|}{ Acute illness in past 12 months } \\
\hline & No* & 1.0 & & 1.0 & \\
\hline & Yes & $0.45(0.32-0.64)$ & 0.0001 & $1.20(1.24-3.21)$ & 0.005 \\
\hline \multicolumn{6}{|c|}{ Limitation of physical activity } \\
\hline & None* & 1.0 & & 1.0 & \\
\hline & Slight & $0.28(0.20-0.40)$ & 0.0001 & $2.92(1.66-5.14)$ & \\
\hline & Moderate & $0.13(0.07-0.23)$ & 0.0001 & $14.16(7.92-25.31)$ & 0.0001 \\
\hline & Severe & $0.14(0.04-0.50)$ & 0.003 & $51.37(24.11-109.41)$ & 0.0001 \\
\hline \multicolumn{6}{|c|}{ Hospitalization in past 12 months } \\
\hline & $\mathrm{No}^{*}$ & 1.0 & & 1.0 & \\
\hline & Yes & $0.53(0.36-0.77)$ & 0.001 & $1.48(1.05-2.07)$ & 0.025 \\
\hline \multicolumn{6}{|l|}{ Hepatitis } \\
\hline & No* & 1.0 & & 1.0 & \\
\hline & Yes & $0.51(0.23-1.17)$ & 0.114 & $1.74(0.93-3.25)$ & 0.081 \\
\hline \multicolumn{6}{|c|}{ Other chronic disease } \\
\hline & No* & 1.0 & & 1.0 & \\
\hline & Yes & $0.56(0.40-0.78)$ & 0.001 & $1.70(1.21-2.36)$ & 0.002 \\
\hline \multicolumn{6}{|c|}{ Access to specialist care as needed } \\
\hline & No* & 1.0 & & 1.0 & \\
\hline & Yes & $2.54(1.27-5.06)$ & 0.008 & $0.79(0.49-1.27)$ & 0.325 \\
\hline \multicolumn{6}{|c|}{ Physician Specialty } \\
\hline & Others* & 1.0 & & 1.0 & \\
\hline & Immunology & $0.96(0.69-1.34)$ & 0.813 & $0.68(0.49-0.94)$ & 0.020 \\
\hline \multicolumn{6}{|c|}{ Regular IVIG treatment } \\
\hline & No* & 1.0 & & 1.0 & \\
\hline & Yes & $1.61(1.07-2.42)$ & 0.023 & $1.01(0.67-1.53)$ & 0.951 \\
\hline
\end{tabular}

*Reference

Significance level $p<0.05$

\section{Discussion}

We used the results from the National Survey of Patients with Primary Immune Deficiency Diseases in America, conducted by the IDF, in an attempt to gain a better understanding of the drivers of PH among patients with PID. Our survey sample was nationally distributed, and based on the single, largest database of persons with PID in the world. Additionally, the 
sampling frame has always been unique; patients who either have been added to the database since the last patient survey, or those who have never participated in an IDF National Patient Survey before. This provided the ability to track down how the patient population known to IDF, may change over time by administering periodic surveys.

Patients' own evaluation of their health is a very simple health measure with important links to patient satisfaction and quality of life [28]. As in most other studies, PH was based on the reply to the global question "How would you describe your current health status?" This has been described as a valid, single measure of health status as it is associated with both disease and subjective self-assessment [29,30]. Perceived health has been demonstrated as predictive of objective health measures including disease burden, health care service utilization, and mortality [3,12,31-33]. A large-scale study of PH in PID employing multivariate analyses has to our knowledge not been performed and thus presents the possibility to truly appreciate what affects patient perceptions of health in this rare disease population.

Our results highlight a number of factors as being significant drivers of PH in PID patients including education level, age, acute and chronic disease, hospitalizations, limitation in physical activity, "on demand" access to specialist care, the specialty of the physician caring for the patient, and regular IVIG replacement therapy.

Several studies demonstrate significant associations between sociodemographic factors and $\mathrm{PH}$, including age, gender and socioeconomic status $[5,34,35]$. The age distribution of the PID patient population, and the mean age of PID patients studied confirm that PID is not simply pediatric condition. In terms of age distribution, the respondents to the 2002 IDF survey are slightly different from other existing databases and registries [36]. The registries aim to cover all the cases occurring in the country, but age distribution in registries depends on the nature of the contributing centers with most of the cases diagnosed in children (e.g., the median age at diagnosis in the French registry is 3.3 years) in some registries, whereas others have a majority of adult cases (e.g., the median age in the Australian registry is 31 years) [37]. Comparing IDF database to USIDNET, another U.S. database, the current age of the patients in the USIDNET registry is 30 years. Based on the IDF data, the average age at which patients were diagnosed with PID was the same as to what the current age of the patient was in USIDNET, which was 30 years (personal communication). So the average age of PID patients in both U.S. databases are similar to each other.

In our study, age was a significant determinant of $\mathrm{PH}$ among PID patients, but only when comparing EVG-PH to G-PH. Our finding suggests that older patients are less likely to have EVG-PH compared to G-PH. This may be due to the fact that in general elderly are more likely to have health problems [33], therefore likely not perceiving their health as excellent or very good. There are other cross-sectional, population based studies reporting of good PH decreased with age [38,39]. In addition to age, the only other sociodemographic characteristic, which was associated with PH in our study, was education level. Patients with college and higher education were more likely to report P-PH. There are inconsistent findings regarding the link between $\mathrm{PH}$ and education status. Our result is in contrast with some published literature [40,41] but consistent with few others [42]. It has been suggested that individuals with higher education might have more health knowledge or contact with health services, making them more accurate predictors of their own health status. Highly educated individuals, however, may have higher expectations about their quality of life and in some research have been linked to being more frequently dissatisfied with their health [43]. In addition, people with higher education levels have been documented as having greater stress levels, which could have a negative impact on PH [24]. In fact, a "dose-response" relation between PH and stress is well documented [44].

Chronic diseases are a particular concern within medicine and have been subject of substantive research as they may last for a patient's entire lifetime, require multiple physician visits, have acute exacerbations necessitating hospital admissions, and leave sequelae. Our findings in PID patients align with previous reports, as patients with chronic disease were more likely to have P-PH compared to patients who reported G-PH. They were also far less likely to report EVG-PH when compared to patients reporting G-PH. Several reports document negative impact of chronic disease on PH $[45,46]$. In addition, PH can predict onset of chronic disease [12]. In a longitudinal study of healthy late midlife U.S. adults, respondents with higher $\mathrm{PH}$ at baseline were less likely to experience subsequent first-time chronic disease including arthritis, diabetes, stroke, coronary heart disease, and lung disease [47]. The relative impact of different chronic diseases on the level of PH has been investigated and results differ depending on the condition evaluated $[23,48]$. As an example, chronic diseases including gastrointestinal, neurological, renal and musculoskeletal disorders had more negative impact on $\mathrm{PH}$ compared to some other chronic diseases such as asthma and diabetes [49]. As an important limitation and like other data in our study, chronic conditions were self-reported. These self reports also did not address individual chronic diseases comprehensively, which would be important to discern as particular chronic conditions have the potential to contribute substantively to $\mathrm{PH}$.

Hospital admission is a known significant driver of $\mathrm{PH}$ and visa-versa and thus the fact that we identified it as an influence upon PH in PID is not a surprise. In a cross-sectional study of 1678 older diabetes patients $\mathrm{PH}$ status was an independent predictor of hospitalization in the following year [50]. A longitudinal study in Sweden, identified associations between $\mathrm{PH}$ and hospital admission in men, but not women, which were attributed to the age differences and follow-up time [51].

Physical health, as might be expected, has consistently been identified as a major predictor of $\mathrm{PH}[52,53]$. 
Longitudinal as well as cross-sectional studies have defined a significant link between acute illness and PH independent of the subjects' chronic illnesses, which are in line with our findings [54,55]. On another note, impact of acute illnesses on PH may not be significant in younger and generally healthy patients [56].

We also found that limitation of physical activity was a very strong predictor of PH in PID. Furthermore, the degree of the limitation had significant impact on $\mathrm{PH}$ with increasing activity limitation significantly decreasing the odds of G-PH. This suggests that the largest contribution to PH among PID patients derives from the extent to which patients can do what they need and want to do. This finding is consistent with results of several studies performed in other diseases $[57,58]$. Along these lines, it has been reported that a patient's perception of disease related to musculoskeletal system was the best predictor of $\mathrm{PH}$ in both men and women [59], and the impact of limitations increases with age [60]. Importantly daily activity is an indicator of independent living [61], and limitation can also predict decline in PH across age groups [62]. Thus, physical activity and perceived limitation likely represent an important focus area to promote improved PH in PID patients and warrant further targeted study.

Our observation of the strong influence of "on demand" access to specialist care upon a PID patient's PH is also consistent with previous studies in other diseases [63]. When compared to other measures of patient satisfaction such as provider and quality of care received, access to care was found to be more strongly associated with PH [28]. Moreover, although not consistent across the literature [64] patients who visited specialists were more satisfied with their health status [28]. We observed only a weak association between PH and physician specialty with patients seeing an immunologist reporting less $\mathrm{P}-\mathrm{PH}$. This suggests at least some importance to PID patients having access to specialized clinical immunologists with regards to their optimal $\mathrm{PH}$.

Many patients with PID are faced with the challenge of lifelong therapy with regular IgG replacement intravenously or subcutaneously in order to reduce susceptibility to and severity of infections. Studies demonstrated improved PH and health related quality of life after initiation of IgG replacement therapy, which was attributed to decreased infection frequency $[65,66]$. Similarly, we found that regular IVIG replacement was significantly associated with EVG-PH. The fact that a specific and indicated therapy links to improved $\mathrm{PH}$ is important to be cognizant of in making treatment decisions as $\mathrm{PH}$ is a strong indicator of future health [58]. Thus patients for whom IgG replacement therapy is indicated should be provided this therapy.

Despite the underlying immune deficiency, about two thirds of patients in our study reported EVG-PH. A previous study of adults with XLA found that with the exception of their $\mathrm{PH}$, patients had a comparable quality of life to that of the general population [26]. This suggests that although XLA has impact on patients' daily lives as determined by missed school/work days or hospitalizations, they can be moderately healthy and lead productive lives [67]. On the contrary, in a study of pediatric XLA patients, perceived psychosocial health was poor despite good perceived physical health [27]. That said, P-PH and reduced family activities in children with PID have been previously identified and attributed to frequent, or serious infections and limitations of physical activity [68]. Differences between adults and children with PID may partially be explained by age-related adaptation and development of coping mechanisms, thus presenting potential strategies to explore through additional research to improve PH. Perceived health is also likely to be a feature of the underlying PID as PH has been found to be lower in CVID as opposed to XLA patients $[67,69]$.

Our findings capture PID patients' own experiences and views of their health in the context of their disease. As such, they indicate that clinical practice should ensure that treatment plans and evaluations focus on the patient rather than the disease. In fact, clinicians could use PH assessment as a tool to uncover patients' problems, and unmet health needs. The potential benefit of using PH measures in clinical practice is that after problems are identified, further care decisions could be linked to patients' priorities and preferences [70]. This can positively drive $\mathrm{PH}$, which is again a significant predictor of future health [58].

In a large study of adults positive $\mathrm{PH}$ changes were associated with better functional well-being and greater survival odds later in life [71]. Unden et al. suggested that irrespective of physician's rating of patient's health during an office visit, those with "poor" $\mathrm{PH}$, perceived lower social and mental well-being, more somatic conditions, and worse coping abilities [10]. Perceived health measures seem to make it practical to look beyond traditional measures of biological functioning to larger issues of functioning and well-being.

Knowledge of a patient's PH could allow for clinical planning that takes into account all of the patient's needs. As some drivers of $\mathrm{PH}$, including chronic/acute disease, and limitation of physical activity significantly influenced $\mathrm{PH}$, the establishment of multidisciplinary health care teams to provide better outpatient and home care services might be helpful for PID patients and certainly worthy of further study with regards to $\mathrm{PH}$. We would suggest that better recognizing the factors that drive PH in PID patients can guide improvements in clinical care and help identify patient health needs. For example, given our findings, interventions to increase physical activity may help improve patients' PH. Similarly; improving health-care access to an immunologist might serve the same purpose. Based upon our findings, we also suggest a distinct potential value to regular preventive screenings to preempt an acute disease, as well as encouragement of regular IgG replacement therapy for patients in whom it is indicated. These should all 
be considered as possible ways to improve PH in PID patients, which again is a known of predictor of future health [58]. In addition, we would recommend a single question assessing a patient's $\mathrm{PH}$ be incorporated into the routine data collected during a clinic visit to allow predictive healthcare modeling.

To the best of our knowledge, this is the first study analyzing $\mathrm{PH}$ in general among patients, and parents of patients with a variety of PID diagnoses based on a national U.S. sample. One of the strengths of our study was that it was based on data derived from a national patient-based survey and data covered several self-reported medical history items. It also captured the respondents' own views of their health. There are limitations, however, including that we used a cross-sectional survey, which makes it difficult to establish the causal relationship between PH and the factors identified. Because of the crosssectional nature of the survey, analyses were limited to the PID diagnoses present at the time of the survey and the impact of other domains specific to that time. Accordingly, our discussion of the trajectories does not contain a comparison group. Also, the data upon which our study was based was selfreported and not independently verified. Thus, there is a possibility of information bias. Finally, selection bias, may have selected for respondents that may have been more health conscious, and therefore, more likely to report better PH. Alternatively, non-respondents may have been in poor health. Although random assignment is preferable for unbiased population estimates, and pediatric survey instruments are available, the survey our data was based on did not target children directly to fill out the distributed surveys. Instead parents/care givers were asked to respond on behalf of children. This survey procedure also introduces some selection bias towards older respondents in households with multiple individuals with PID. The selection bias may be minimized utilizing a pediatric survey tool for future studies. In some cases in surveys, one might ask the same questions of the parent-proxy and of the child. This essentially means having at least two surveys completed for each minor child, one from the proxy and one from the child. Although it might be interesting to compare the results, determining which answer to use if there are differences between responses for a child is problematic. Additionally, the cost involved to conduct the survey with multiple instruments for a family, both in complexity, potential respondent burden and in true monetary costs would be beyond the scope of the goals for the survey.

Our results, however, define some relevant signal and create rationale for further evaluation of PH in PID. We propose that a longitudinal study is needed to further clarify contribution of various factors to $\mathrm{PH}$ of patients with PID.

The strength of measures of general health perceptions lies in their subjectivity and that patient values will help shape the goals and means of medical care [72]. Our results suggest that clinical care of patients with PID should be tailored to the patients' specific characteristics and needs to achieve better patient outcomes. As patient outcomes research progresses, each step in this direction brings medicine closer to pursuing "what really matters to our patients?" rather than "what is the matter with our patients?"

Conflict of Interest Jordan S. Orange is a consultant for CSL Behring, Baxter, ADMA, Walgreens, ASD, and Atlantic Research. Jordan S. Orange also received research grants to institution from CSL Behring, and is a member of IDF Advisory Board, and JMF Scientific Committee.

Open Access This article is distributed under the terms of the Creative Commons Attribution 4.0 International License (http:// creativecommons.org/licenses/by/4.0/), which permits unrestricted use, distribution, and reproduction in any medium, provided you give appropriate credit to the original author(s) and the source, provide a link to the Creative Commons license, and indicate if changes were made.

\section{References}

1. Jylha M. What is self-rated health and why does it predict mortality? Towards a unified conceptual model. Soc Sci Med. 2009;69(3): 307-16.

2. Moss NE. Gender equity and socioeconomic inequality: a framework for the patterning of women's health. Soc Sci Med. 2002;54(5):649-61.

3. Idler EL, Benyamini Y. Self-rated health and mortality: a review of twenty-seven community studies. J Health Soc Behav. 1997;38(1): 21-37.

4. Idler EL, Russell LB, Davis D. Survival, functional limitations, and self-rated health in the NHANES I Epidemiologic Follow-up Study, 1992. First National Health and Nutrition Examination Survey. Am J Epidemiol. 2000;152(9):874-83.

5. Shields M, Shooshtari S. Determinants of self-perceived health. Health Rep. 2001;13(1):35-52.

6. Fayers PM, Sprangers MA. Understanding self-rated health. Lancet. 2002;359(9302):187-8.

7. Smith PM, Glazier RH, Sibley LM. The predictors of self-rated health and the relationship between self-rated health and health service needs are similar across socioeconomic groups in Canada. J Clin Epidemiol. 2010;63(4):412-21.

8. Miilunpalo S, Vuori I, Oja P, Pasanen M, Urponen H. Self-rated health status as a health measure: the predictive value of selfreported health status on the use of physician services and on mortality in the working-age population. J Clin Epidemiol. 1997;50(5): 517-28.

9. Wilcox VL, Kas1 SV, Idler EL. Self-rated health and physical disability in elderly survivors of a major medical event. J Gerontol Ser B Psychol Sci Soc Sci. 1996;51(2):S96-104.

10. Unden AL, Elofsson S. Health from the patient's point of view. How does it relate to the physician's judgement? Fam Pract. 2001;18(2):174-80.

11. Vissandjee B, Desmeules M, Cao Z, Abdool S. Integrating socioeconomic determinants of Canadian Women's health. BMC Womens Health. 2004;4(1):S34.

12. Goldberg P, Gueguen A, Schmaus A, Nakache JP, Goldberg M. Longitudinal study of associations between perceived health status and self reported diseases in the French Gazel cohort. J Epidemiol Community Health. 2001;55(4):233-8.

13. Tabolli S, Giannantoni P, Pulvirenti F, La Marra F, Granata G, Milito C, et al. Longitudinal study on health-related quality of life 
in a cohort of 96 patients with common variable immune deficiencies. Front Immunol. 2014;5:605.

14. Nguyen TV, Bosset JF, Monnier A, Fournier J, Perrin V, Baumann $\mathrm{C}$, et al. Determinants of patient satisfaction in ambulatory oncology: a cross sectional study based on the OUT-PATSAT35 questionnaire. BMC Cancer. 2011;11:526.

15. Westaway MS, Rheeder P, Van Zyl DG, Seager JR. Interpersonal and organizational dimensions of patient satisfaction: the moderating effects of health status. Int J Qual Health Care : J Int Soc Qual Health Care / ISQua. 2003;15(4):337-44.

16. Cesari M, Onder G, Zamboni V, Manini T, Shorr RI, Russo A, et al. Physical function and self-rated health status as predictors of mortality: results from longitudinal analysis in the ilSIRENTE study. BMC Geriatr. 2008;8:34.

17. Nery Guimaraes JM, Chor D, Werneck GL, Carvalho MS, Coeli CM, Lopes CS, et al. Association between self-rated health and mortality: 10 years follow-up to the Pro-Saude cohort study. BMC Public Health. 2012;12:676.

18. Desalvo KB, Muntner P. Discordance between physician and patient self-rated health and all-cause mortality. Ochsner J. 2011;11(3):232-40.

19. Benyamini Y. Why does self-rated health predict mortality? An update on current knowledge and a research agenda for psychologists. Psychol Health. 2011;26(11):1407-13.

20. Malterud K, Hollnagel H. Positive self-assessed general health in patients with medical problems. A qualitative study from general practice. Scand J Prim Health Care. 2004;22(1):11-5.

21. Kennedy BP, Kawachi I, Glass R, Prothrow-Stith D. Income distribution, socioeconomic status, and self rated health in the United States: multilevel analysis. BMJ. 1998;317(7163):917-21.

22. Da Costa D, Clarke AE, Dobkin PL, Senecal JL, Fortin PR, Danoff DS, et al. The relationship between health status, social support and satisfaction with medical care among patients with systemic lupus erythematosus. Int J Qual Health Care : J Int Soc Qual Health Care / ISQua. 1999;11(3):201-7.

23. Putcha N, Puhan MA, Hansel NN, Drummond MB, Boyd CM. Impact of co-morbidities on self-rated health in self-reported COPD: an analysis of NHANES 2001-2008. COPD. 2013;10(3): 324-32.

24. Tang LY, Nabalamba A, Graff LA, Bernstein CN. A comparison of self-perceived health status in inflammatory bowel disease and irritable bowel syndrome patients from a Canadian national population survey. Canadian journal of gastroenterology. J Can Gastroenterol. 2008;22(5):475-83.

25. Sullivan PW, Smith KL, Ghushchyan VH, Globe DR, Lin SL, Globe G. Asthma in USA: its impact on health-related quality of life. J Asthma : Off J Assoc Care of Asthma. 2013;50(8):891-9.

26. Howard V, Greene JM, Pahwa S, Winkelstein JA, Boyle JM, Kocak $\mathrm{M}$, et al. The health status and quality of life of adults with X-linked agammaglobulinemia. Clin Immunol. 2006;118(2-3):201-8.

27. Soresina A, Nacinovich R, Bomba M, Cassani M, Molinaro A, Sciotto A, et al. The quality of life of children and adolescents with X-linked agammaglobulinemia. J Clin Immunol. 2009;29(4):501-7.

28. Xiao H, Barber JP. The effect of perceived health status on patient satisfaction. Value Health : J Int Soc Pharmacoecon Outcomes Res. 2008;11(4):719-25.

29. Hunt SM, McKenna SP, McEwen J, Backett EM, Williams J, Papp E. A quantitative approach to perceived health status: a validation study. J Epidemiol Community Health. 1980;34(4):281-6.

30. Segovia J, Bartlett RF, Edwards AC. An empirical analysis of the dimensions of health status measures. Soc Sci Med. 1989;29(6): 761-8.

31. Tsai MC, Lin SH, Chou YY, Lin SJ. Exploration of health status, healthcare utilization, and health service expectations among Taiwanese adolescents. Eur J Pediatr. 2014;173(2):187-96.
32. Dominick KL, Ahern FM, Gold CH, Heller DA. Relationship of health-related quality of life to health care utilization and mortality among older adults. Aging Clin Exp Res. 2002;14(6):499-508.

33. McFadden E, Luben R, Bingham S, Wareham N, Kinmonth AL, Khaw KT. Does the association between self-rated health and mortality vary by social class? Soc Sci Med. 2009;68(2):275-80.

34. Sundquist J, Johansson SE. Self reported poor health and low educational level predictors for mortality: a population based follow up study of 39,156 people in Sweden. J Epidemiol Community Health. 1997;51(1):35-40.

35. Molarius A, Berglund K, Eriksson C, Lambe M, Nordstrom E, Eriksson HG, et al. Socioeconomic conditions, lifestyle factors, and self-rated health among men and women in Sweden. Eur J Pub Health. 2007;17(2):125-33.

36. Modell V, Knaus M, Modell F, Roifman C, Orange J, Notarangelo LD. Global overview of primary immunodeficiencies: a report from Jeffrey Modell Centers worldwide focused on diagnosis, treatment, and discovery. Immunol Res. 2014;60(1):132-44.

37. Bousfiha AA, Jeddane L, Ailal F, Benhsaien I, Mahlaoui N, Casanova JL, et al. Primary immunodeficiency diseases worldwide: more common than generally thought. J Clin Immunol. 2013;33(1):1-7.

38. Darviri C, Artemiadis AK, Tigani X, Alexopoulos EC. Lifestyle and self-rated health: a cross-sectional study of 3,601 citizens of Athens, Greece. BMC Pubic Health. 2011;11:619.

39. Chan YY, Teh CH, Lim KK, Lim KH, Yeo PS, Kee CC, et al. Lifestyle, chronic diseases and self-rated health among Malaysian adults: results from the 2011 National Health and Morbidity Survey (NHMS). BMC Public Health. 2015;15(1):754.

40. Heistaro S, Jousilahti P, Lahelma E, Vartiainen E, Puska P. Self rated health and mortality: a long term prospective study in eastern Finland. J Epidemiol Community Health. 2001;55(4):227-32.

41. Dowd JB, Zajacova A. Does the predictive power of self-rated health for subsequent mortality risk vary by socioeconomic status in the US? Int J Epidemiol. 2007;36(6):1214-21.

42. Whitehead M, Drever F, Doran T. Is the health of the long-term unemployed better or worse in high unemployment areas? Health Stat Q / Off Nat Stat. 2005;25:12-7.

43. Delpierre C, Lauwers-Cances V, Datta GD, Lang T, Berkman L. Using self-rated health for analysing social inequalities in health: a risk for underestimating the gap between socioeconomic groups? J Epidemiol Community Health. 2009;63(6):426-32.

44. Hillen T, Schaub R, Hiestermann A, Kirschner W, Robra BP. Self rating of health is associated with stressful life events, social support and residency in East and West Berlin shortly after the fall of the wall. J Epidemiol Community Health. 2000;54(8):575-80.

45. Ware Jr JE, Bayliss MS, Mannocchia M, Davis GL. Health-related quality of life in chronic hepatitis $\mathrm{C}$ : impact of disease and treatment response. Int Ther Group Hepatol. 1999;30(2):550-5.

46. Westaway MS. The impact of chronic diseases on the health and well-being of South Africans in early and later old age. Arch Gerontol Geriatr. 2010;50(2):213-21.

47. Latham K, Peek CW. Self-rated health and morbidity onset among late midlife U.S. adults. J Gerontol Ser B Psychol Sci Soc Sci. 2013;68(1):107-16.

48. Sprangers MA, de Regt EB, Andries F, van Agt HM, Bijl RV, de Boer JB, et al. Which chronic conditions are associated with better or poorer quality of life? J Clin Epidemiol. 2000;53(9):895-907.

49. Molarius A, Janson S. Self-rated health, chronic diseases, and symptoms among middle-aged and elderly men and women. J Clin Epidemiol. 2002;55(4):364-70.

50. Li CL, Chang HY, Wang HH, Bai YB. Diabetes, functional ability, and self-rated health independently predict hospital admission within 1 year among older adults: a population based cohort study. Arch Gerontol Geriatr. 2011;52(2):147-52. 
51. Halford C, Wallman T, Welin L, Rosengren A, Bardel A, Johansson $\mathrm{S}$, et al. Effects of self-rated health on sick leave, disability pension, hospital admissions and mortality. A population-based longitudinal study of nearly 15,000 observations among Swedish women and men. BMC Public Health. 2012;12:1103.

52. Manor O, Matthews S, Power C. Self-rated health and limiting longstanding illness: inter-relationships with morbidity in early adulthood. Int J Epidemiol. 2001;30(3):600-7.

53. Chen Y, While AE, Hicks A. Self-rated health and associated factors among older people living alone in Shanghai. Geriatr Gerontolo Int. 2014 Apr 21

54. Bailis DS, Segall A, Chipperfield JG. Two views of self-rated general health status. Soc Sci Med. 2003;56(2):203-17.

55. Meng Q, Xie Z, Zhang T. A single-item self-rated health measure correlates with objective health status in the elderly: a survey in suburban beijing. Front Public Health. 2014;2:27.

56. Goldstein MS, Siegel JM, Boyer R. Predicting changes in perceived health status. Am J Public Health. 1984;74(6):611-4.

57. Foottit J, Anderson D. Associations between perception of wellness and health-related quality of life, comorbidities, modifiable lifestyle factors and demographics in older Australians. Aust J Ageing. 2012;31(1):22-7.

58. Benyamini Y, Blumstein T, Murad H, Lerner-Geva L. Changes over time from baseline poor self-rated health: for whom does poor selfrated health not predict mortality? Psychol Health. 2011;26(11): 1446-62.

59. Fylkesnes K, Forde OH. The tromso study: predictors of selfevaluated health-has society adopted the expanded health concept? Soc Sci Med. 1991;32(2):141-6.

60. Onadja Y, Bignami S, Rossier C, Zunzunegui MV. The components of self-rated health among adults in Ouagadougou. Burkina Faso Popul Health Metrics. 2013;11:15.

61. Bize R, Johnson JA, Plotnikoff RC. Physical activity level and health-related quality of life in the general adult population: a systematic review. Prev Med. 2007;45(6):401-15.
62. Sargent-Cox K, Cherbuin N, Morris L, Butterworth P, Anstey KJ. The effect of health behavior change on self-rated health across the adult life course: a longitudinal cohort study. Prev Med. 2014;58:75-80.

63. Dickerson JB, Smith ML, Ahn S, Ory MG. Associations between health care factors and self-reported health status among individuals with diabetes: results from a community assessment. J Community Health. 2011;36(2):332-41.

64. Shi L, Starfield B, Politzer R, Regan J. Primary care, self-rated health, and reductions in social disparities in health. Health Serv Res. 2002;37(3):529-50.

65. Gardulf A, Bjorvell H, Gustafson R, Hammarstrom L, Smith CI. The life situations of patients with primary antibody deficiency untreated or treated with subcutaneous gammaglobulin infusions. Clin Exp Immunol. 1993;92(2):200-4.

66. Gardulf A, Nicolay U. Replacement IgG therapy and self-therapy at home improve the health-related quality of life in patients with primary antibody deficiencies. Curr Opin Allergy Clin Immunol. 2006;6(6):434-42.

67. Winkelstein JA, Conley ME, James C, Howard V, Boyle J. Adults with X-linked agammaglobulinemia: impact of disease on daily lives, quality of life, educational and socioeconomic status, knowledge of inheritance, and reproductive attitudes. Medicine. 2008;87(5):253-8.

68. Zebracki K, Palermo TM, Hostoffer R, Duff K, Drotar D. Healthrelated quality of life of children with primary immunodeficiency disease: a comparison study. Ann Allergy, Asthma Immunol: Off Publ Am Coll Allergy, Asthma Immunol. 2004;93(6):557-61.

69. Quinti I, Di Pietro C, Martini H, Pesce AM, Lombardi F, Baumghartner $\mathrm{M}$, et al. Health related quality of life in common variable immunodeficiency. Yonsei Med J. 2012;53(3):603-10.

70. Higginson IJ, Carr AJ. Measuring quality of life: using quality of life measures in the clinical setting. BMJ. 2001;322(7297):1297-300.

71. Ruthig JC, Hanson BL, Pedersen H, Weber A, Chipperfield JG. Later life health optimism, pessimism and realism: psychosocial contributors and health correlates. Psychol Health. 2011;26(7):835-53.

72. Sullivan M. The new subjective medicine: taking the patient's point of view on health care and health. Soc Sci Med. 2003;56(7):1595-604. 